\title{
Nitrogen Cycling in Soybean Rhizosphere: Sources and Sinks of Nitrous Oxide $\left(\mathrm{N}_{2} \mathrm{O}\right)$
}

\author{
Cristina Sánchez* and Kiwamu Minamisawa* \\ Graduate School of Life Sciences, Tohoku University, Sendai, Japan
}

Nitrous oxide $\left(\mathrm{N}_{2} \mathrm{O}\right)$ is the third most important greenhouse gas after carbon dioxide and methane, and a prominent ozone-depleting substance. Agricultural soils are the primary anthropogenic source of $\mathrm{N}_{2} \mathrm{O}$ because of the constant increase in the use of industrial nitrogen $(\mathrm{N})$ fertilizers. The soybean crop is grown on $6 \%$ of the world's arable land, and its production is expected to increase rapidly in the future. In this review, we summarize the current knowledge on $\mathrm{N}$-cycle in the rhizosphere of soybean plants, particularly sources and sinks of $\mathrm{N}_{2} \mathrm{O}$. Soybean root nodules are the host of dinitrogen $\left(\mathrm{N}_{2}\right)$-fixing bacteria from the genus Bradyrhizobium. Nodule decomposition is the main source of $\mathrm{N}_{2} \mathrm{O}$ in soybean rhizosphere, where soil organisms mediate the nitrogen transformations that produce $\mathrm{N}_{2} \mathrm{O}$. This $\mathrm{N}_{2} \mathrm{O}$ is either emitted into the atmosphere or further reduced to $\mathrm{N}_{2}$ by the bradyrhizobial $\mathrm{N}_{2} \mathrm{O}$ reductase $\left(\mathrm{N}_{2} \mathrm{OR}\right)$, encoded by the nos gene cluster. The dominance of nos ${ }^{-}$indigenous populations of soybean bradyrhizobia results in the emission of $\mathrm{N}_{2} \mathrm{O}$ into the atmosphere. Hence, inoculation with nos ${ }^{+}$or nos ${ }^{++}$(mutants with enhanced $\mathrm{N}_{2} \mathrm{OR}$ activity) bradyrhizobia has proved to be promising strategies to reduce $\mathrm{N}_{2} \mathrm{O}$ emission in the field. We discussed these strategies, the molecular mechanisms underlying them, and the future perspectives to develop better options for global mitigation of $\mathrm{N}_{2} \mathrm{O}$ emission from soils.

Keywords: Bradyrhizobium, soybean, rhizosphere, denitrification, $\mathrm{N}_{2} \mathrm{O}$ reductase, nos regulation, greenhouse gas, mitigation strategies

\section{NITROGEN TRANSFORMATIONS IN SOYBEAN RHIZOSPHERE: $\mathrm{N}_{2} \mathrm{O}$ IS EMITTED DUE TO NODULE DECOMPOSITION}

The term, "rhizosphere" was first defined by Lorenz Hiltner as the soil compartment influenced by plant roots. Since then, the rhizosphere has received widespread attention from scientists in different disciplines as a hotspot for intra-microbial and plant-microbe interactions (Hartmann et al., 2008; Bakker et al., 2013). Nitrogen (N), an essential component in living organisms, is the most common limiting nutrient for plant growth in agricultural soils (LeBauer and Treseder, 2008). Fixation of dinitrogen $\left(\mathrm{N}_{2}\right)$ into ammonia $\left(\mathrm{NH}_{3}\right)$ by legume-associated endosymbiotic bacteria, generally known as rhizobia, is a major source of $\mathrm{N}$ in soils, and is an agriculturally and ecologically crucial process to reduce plant dependence on industrial $\mathrm{N}$ fertilizers. Rhizobia are hosted within the nodules formed in the roots as the result of the symbiosis; inside the nodules, rhizobial cells encounter oxygen-limiting conditions that are required for the synthesis and activity of nitrogenase that converts $\mathrm{N}_{2}$ into $\mathrm{NH}_{3}$ (Figure 1). Thus, rhizobia provide $\mathrm{N}$ to the host plant, which in return, 
supplies photosynthetically fixed carbon to the bacteria. Although rhizobia have been extensively studied as inhabitants of legume nodules, only few studies have focused on them as denitrifiers in the legume rhizosphere (Inaba et al., 2009, 2012; Shiina et al., 2014; Saeki et al., 2017).

Soybean [Glycine max (L.) Merr.] is grown on $6 \%$ of the world's arable land. Its production increased from 17 to 230 million metric tons in the past 50 years, and is expected to increase rapidly in the future due to an increased demand for soybean meal and oil (Uchida and Akiyama, 2013). Soybean generally hosts rhizobia from the genus Bradyrhizobium (Argaw, 2014). In addition to fixing $\mathrm{N}_{2}$, many soybean-associated Bradyrhizobium strains contain genes for some, or all of the four denitrification reductases. Denitrification is an alternate respiratory process in which the oxidized forms of $\mathrm{N}$ in the soil - nitrate $\left(\mathrm{NO}_{3}{ }^{-}\right)$and nitrite $\left(\mathrm{NO}_{2}{ }^{-}\right)$- are used as electron acceptors in oxygen limiting conditions. $\mathrm{NO}_{2}{ }^{-}$ is reduced to nitric oxide (NO), nitrous oxide $\left(\mathrm{N}_{2} \mathrm{O}\right)$, and $\mathrm{N}_{2}$ gases, which are returned to the atmosphere (Figure 1). The complete denitrification pathway in soybean bradyrhizobia requires four enzymes, periplasmic $\mathrm{NO}_{3}{ }^{-}$reductase (Nap), copper $(\mathrm{Cu})$-containing $\mathrm{NO}_{2}{ }^{-}$reductase (NirK), c-type $\mathrm{NO}$ reductase (cNor), and $\mathrm{N}_{2} \mathrm{O}$ reductase $\left(\mathrm{N}_{2} \mathrm{OR}\right)$ (Figure 1). Bradyrhizobial denitrification is functional under both free-living (for example, in the soybean rhizosphere) and symbiotic (inside the root nodules) conditions (Sameshima-Saito et al., 2006a; Sánchez et al., 2011; Inaba et al., 2012).

$\mathrm{N}_{2} \mathrm{O}$ is the third most important greenhouse gas after carbon dioxide $\left(\mathrm{CO}_{2}\right)$ and methane $\left(\mathrm{CH}_{4}\right)$ and is currently the major ozone-depleting compound in the stratosphere (Hénault et al., 2012; Thomson et al., 2012). Terrestrial ecosystems are the main source of $\mathrm{N}_{2} \mathrm{O}$, primarily due to the use of industrial $\mathrm{N}$ fertilizers in agriculture (Hénault et al., 2012; Thomson et al., 2012; Intergovernmental Panel on Climate Change [IPCC], 2014). The soybean rhizosphere is a hotspot for $\mathrm{N}$ transformations including production and removal of $\mathrm{N}_{2} \mathrm{O}$. Nodule decomposition is a major source of $\mathrm{N}_{2} \mathrm{O}$, particularly in soybean ecosystems, compared to other possible sources including aboveground plant residues. Inaba et al. (2009) showed that $\mathrm{N}_{2} \mathrm{O}$ is only emitted by decomposed nodules, but not by fresh nodules or roots. Studies showed that $\mathrm{N}_{2} \mathrm{O}$ emission not only occurs from decomposed nodules after soybean harvesting, but also starts before the harvest till the late growth period (Yang and Cai, 2005; Inaba et al., 2012; reviewed by Uchida and Akiyama, 2013). Biological $\mathrm{N}_{2}$ fixation is an important indirect source for $\mathrm{N}_{2} \mathrm{O}$ during nodule decomposition. Indeed, a ${ }^{15} \mathrm{~N}$ tracer experiment revealed that the $\mathrm{N}_{2} \mathrm{O}$ emitted from the soybean rhizosphere was almost entirely derived from $\mathrm{N}_{2}$ fixed symbiotically in the nodules (Inaba et al., 2012; Figure 1). During nodule decomposition, rhizospheric microbes are essential for $\mathrm{N}_{2} \mathrm{O}$ emission; organic $\mathrm{N}$ from the nodule is mineralized into ammonium $\left(\mathrm{NH}_{4}{ }^{+}\right.$, Figure 1); $\mathrm{N}_{2} \mathrm{O}$ is then produced via nitrification and denitrification (Inaba et al., 2009, 2012; Figure 1). Although soybean bradyrhizobia are important players in denitrification (responsible for $\sim 41 \%$ of the total $\mathrm{N}_{2} \mathrm{O}$ produced), but other denitrifying microorganisms are also important contributors $\left(\sim 59 \%\right.$ of the total $\mathrm{N}_{2} \mathrm{O}$ produced;
Inaba et al., 2012). Populations of nematodes, protozoans, and fungi were markedly enhanced in the soybean rhizosphere of decomposing nodules, suggesting that these organisms contributed to the complex $\mathrm{N}$ transformation (Inaba et al., 2009). $\mathrm{N}_{2} \mathrm{O}$ formed by denitrification is either emitted into the atmosphere or is further reduced to $\mathrm{N}_{2}$ by $\mathrm{N}_{2} \mathrm{O}$ reductase of soybean bradyrhizobia (Sameshima-Saito et al., 2004, 2006b; Inaba et al., 2012; Figure 1). In soybean fields, both $\mathrm{N}_{2}$ - and $\mathrm{N}_{2} \mathrm{O}$-producing soybean bradyrhizobia strains coexist; therefore soybean roots are infected with multiple bradyrhizobial strains that differ in denitrifying activity (Sameshima-Saito et al., 2004, 2006b; Shiina et al., 2014). Thus, the flux of $\mathrm{N}_{2} \mathrm{O}$ from soybean fields during nodule decomposition is partly determined by biotic factors like the balance between $\mathrm{N}_{2} \mathrm{O}$ emission by soil microbes whose denitrification produce $\mathrm{N}_{2} \mathrm{O}$ (including bradyrhizobia) and $\mathrm{N}_{2} \mathrm{O}$ uptake by soybean bradyrhizobia that produce $\mathrm{N}_{2} \mathrm{OR}$ (Inaba et al., 2012; Figure 1).

\section{NITROUS OXIDE REDUCTASE: THE KEY ENZYME TO REDUCE $\mathrm{N}_{2} \mathrm{O}$ EMISSION}

$\mathrm{N}_{2} \mathrm{OR}$ is a Cu-containing enzyme that catalyzes the two-electron reduction of $\mathrm{N}_{2} \mathrm{O}$ to $\mathrm{N}_{2}$, which is the only known pathway for the removal of $\mathrm{N}_{2} \mathrm{O}$ from ecosystems (Richardson et al., 2009). Therefore, the expression and activity of $\mathrm{N}_{2} \mathrm{OR}$ is a natural target to mitigate $\mathrm{N}_{2} \mathrm{O}$ emission from agricultural soils.

In Bradyrhizobium diazoefficiens (reclassified from Bradyrhizobium japonicum by Delamuta et al., 2013), the $\mathrm{N}_{2} \mathrm{OR}$ (NosZ) and its accessory functions are encoded by nosRZDYFLX gene cluster (Velasco et al., 2004). The flavoproteins NosR and NosX form an electron transport pathway from the quinone pool to NosZ; NosR is also required for the transcription of nos genes (Velasco et al., 2004; Zumft and Kroneck, 2007). NosD, NosF, NosY, and NosL are involved in maturation of the $\mathrm{Cu}_{Z}$ site of NosZ (Zumft and Kroneck, 2007). Although the reduction of $\mathrm{N}_{2} \mathrm{O}$ to $\mathrm{N}_{2}$ by $\mathrm{N}_{2} \mathrm{OR}$ is integrated as the last step of the denitrification pathway, it can provide a benefit for $\mathrm{N}_{2} \mathrm{O}$ respiration as a separate module. When $\mathrm{N}_{2} \mathrm{O}$ is provided as the sole electron acceptor to $B$. diazoefficiens, anaerobic respiration and growth are sustained by reducing $\mathrm{N}_{2} \mathrm{O}$ to $\mathrm{N}_{2}$ (Zumft, 1997; Sánchez et al., 2013; Graf et al., 2014).

Bradyrhizobium diazoefficiens carries the nos gene cluster $\left(\right.$ nos $^{+}$) and denitrifies $\mathrm{NO}_{3}{ }^{-}$to $\mathrm{N}_{2}$, whereas other soybean bradyrhizobia including $B$. japonicum lack the nos gene cluster (nos ${ }^{-}$) and cannot reduce $\mathrm{N}_{2} \mathrm{O}$ to $\mathrm{N}_{2}$ (Sameshima-Saito et al., 2004, 2006b; Inaba et al., 2012). Sameshima-Saito et al. (2006a) showed that soybean roots nodulated with $B$. diazoefficiens could scavenge very low concentrations of exogenous $\mathrm{N}_{2} \mathrm{O}$, equivalent to the natural concentration of $\mathrm{N}_{2} \mathrm{O}$ in air $(\sim 0.34 \mathrm{ppm}$; Badr and Probert, 1992). Later, pot studies demonstrated that soybean roots inoculated with nos $^{+}$strains have the potential to reduce $\mathrm{N}_{2} \mathrm{O}$ derived from decomposing nodules and other $\mathrm{N}$ sources from fertilizer and soil organic matter (Hénault and Revellin, 2011; Inaba et al., 2012; Uchida and Akiyama, 2013). Thus, Bradyrhizobium nos ${ }^{+}$strain inoculation is a promising strategy for mitigating $\mathrm{N}_{2} \mathrm{O}$ emission at the field scale. This 


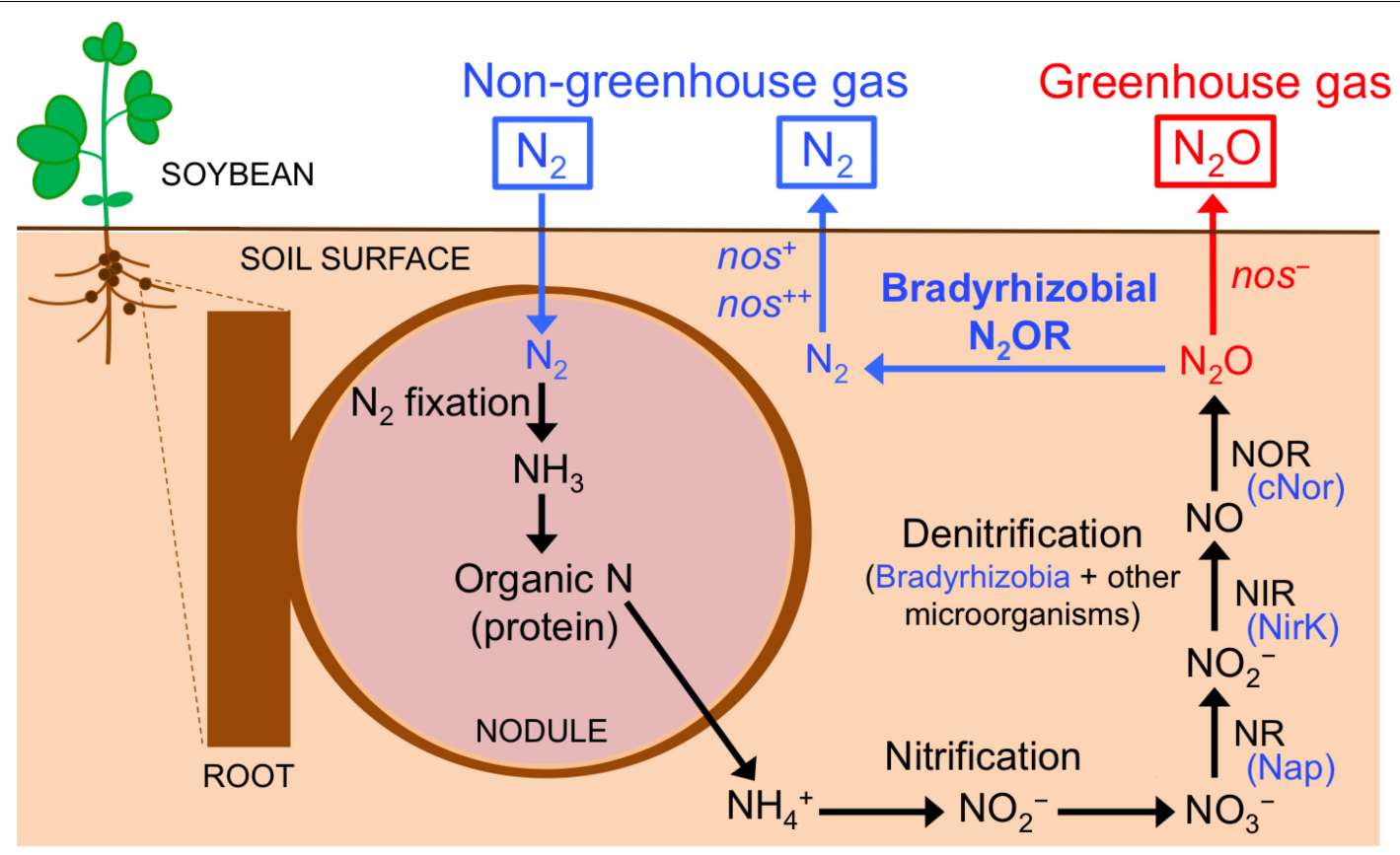

FIGURE 1 | Nitrogen transformations in soybean rhizosphere. Organic nitrogen in the nodule is mineralized into $\mathrm{NH}_{4}{ }^{+}$that will be transformed into $\mathrm{N}_{2} \mathrm{O}$ through nitrification and denitrification processes. Soybean bradyrhizobia (blue) and other microorganisms contribute to the denitrification process. The $\mathrm{N}_{2} \mathrm{O}$ formed is either emitted into the atmosphere (red) or further reduced to $\mathrm{N}_{2}$ exclusively by soybean bradyrhizobia that produce $\mathrm{N}_{2} \mathrm{O}$ reductase ( $\mathrm{N}_{2} \mathrm{OR}$; blue). Nase, nitrogenase; $\mathrm{NR}$, dissimilatory nitrate reductase; Nap, periplasmic nitrate reductase; NIR, dissimilatory nitrite reductase; NirK, Cu-containing nitrite reductase; NOR, nitric oxide reductase; cNor, c-type nitric oxide reductase. See text for more details.

is likely effective in soybean soils that act as an $\mathrm{N}_{2} \mathrm{O}$ source, a condition that potentially arises from several situations like (i) indigenous bradyrhizobia community being dominated by nos $^{-}$species (Sameshima-Saito et al., 2004, 2006b; Shiina et al., 2014), (ii) anoxic conditions such as waterlogging that induce $\mathrm{N}_{2} \mathrm{O}$ emissions from denitrification by Bradyrhizobium (Tortosa et al., 2016) and other microorganisms, and (iii) increased $\mathrm{NO}_{3}{ }^{-}$ supply as a consequence of heavy $\mathrm{N}$ fertilization leading to increased $\mathrm{N}_{2} \mathrm{O}$ emission from intact soybean root systems via bradyrhizobial denitrification (Ciampitti et al., 2008; Hirayama et al., 2011; Inaba et al., 2012).

Among the $\mathrm{N}_{2} \mathrm{O}$-mitigation options for agricultural soils, the first biological method for the field scale was described by Itakura et al. (2013). Mutants of $B$. diazoefficiens USDA110 with a high nos expression and $\mathrm{N}_{2} \mathrm{OR}$ activity (nos ${ }^{++}$strains) were generated by a mutational strategy (Itakura et al., 2008). This strategy involved (1) introduction of a plasmid containing a mutated dnaQ gene (pKQ2) to enhance replication error on the $B$. diazoefficiens genome by disrupting the exonuclease proofreading activity of DNA polymerase, (2) enrichment culture under selection pressure favoring anaerobic $\mathrm{N}_{2} \mathrm{O}$ respiration, and (3) elimination of the $\mathrm{pKQ} 2$ plasmid by nodulation. Thus, the resulting mutants were not genetically modified organisms (GMOs). The nos ${ }^{++}$mutants retained higher nos expression and $\mathrm{N}_{2} \mathrm{OR}$ activity in both free-living and symbiotic cells than the wild-type nos $^{+}$strains (Itakura et al., 2013; Sánchez et al., 2014). Comparative analysis of the nos $^{++}$mutant genomes revealed the mechanism underlying the nos ${ }^{++}$phenotype, a point mutation in nasS gene encoding the $\mathrm{NO}_{3}{ }^{-}$sensor of the two-component NasST regulatory system (Sánchez et al., 2014, 2017), which will be discussed later.

The effectiveness of $\mathrm{N}_{2} \mathrm{O}$ emission mitigation by the nos ${ }^{++}$ mutant was first confirmed under simulated field conditions in a pot experiment with Andosol soil, which predominantly contains nos ${ }^{-}$bradyrhizobia (Itakura et al., 2013). $\mathrm{N}_{2} \mathrm{O}$ emission from the Andosol soil inoculated with the nos ${ }^{++}$mutant strain was significantly reduced compared with that inoculated with wild-type nos $^{+}$strain. Itakura et al. (2013) demonstrated that inoculation of nos ${ }^{++}$strains to growing soybean in Andosol soil reduced postharvest $\mathrm{N}_{2} \mathrm{O}$ emission by $43 \%$ in the lysimeter study and by $54 \%$ in the farm-scale study. However, reduction in postharvest $\mathrm{N}_{2} \mathrm{O}$ emission by inoculation with the nos ${ }^{++}$ strains was not significant in a Gleysol soil, which predominantly contains nos ${ }^{+}$bradyrhizobia, although the nos ${ }^{++}$strains clearly showed higher $\mathrm{N}_{2} \mathrm{O}$-reducing potential than that of the nos ${ }^{+}$ strains under laboratory conditions (Itakura et al., 2013; Shiina et al., 2014). Thus, some factors present in the soybean rhizosphere of Gleysol soil limited the potential $\mathrm{N}_{2} \mathrm{O}$ mitigation ability of the $n o s^{++}$strains.

A recent report showed that inoculation of soil with a mixed and enriched culture of indigenous nos ${ }^{+}$strains of the B. diazoefficiens USDA110 group isolated from agricultural fields efficiently mitigated $\mathrm{N}_{2} \mathrm{O}$ emission (Akiyama et al., 2016). As in the nos ${ }^{++}$approach above, inoculation with the mixed culture was successful in soils dominated by nos ${ }^{-}$bradyrhizobia. Additionally, this mixture is expected to be more competitive and 
adaptable to changing environmental factors than a single strain (Akiyama et al., 2016). This method is an alternative to GMOs and overcomes the problem of strong opposition to them.

\section{REGULATION OF $\mathrm{N}_{2} \mathrm{O}$ REDUCTASE GENES IN BRADYRHIZOBIA}

Considering the importance of $\mathrm{N}_{2} \mathrm{OR}$ in $\mathrm{N}_{2} \mathrm{O}$ removal from ecosystems, significant progress has been made in understanding its genetic regulation in bacteria, especially in the denitrifying bacteria, Paracoccus denitrificans (reviewed by Gaimster et al., 2018), and B. diazoefficiens as a model for denitrification in legume-associated rhizobia. In the latter bacterium, the $n o s R$ gene is constitutively expressed at a low level from the promoter $\mathrm{P}_{a}$ in aerobiosis, but is strongly induced from the promoter $\mathrm{P}_{d}$ under denitrifying conditions (i.e., anoxia with $\mathrm{NO}_{3}^{-}$as electron acceptor), which is dependent on the oxygen-responsive regulatory cascade FixLJ-FixK ${ }_{2}$ (Torres et al., 2016, 2017; Sánchez et al., 2017; Figure 2A). Decreasing oxygen level to $5 \%$ during a culture triggers ATP-dependent autophosphorylation of the heme-based sensor kinase, FixL to phosphorylate the response regulator FixJ, which activates FixK $_{2}$, a transcriptional activator that directly interacts with the nosR promoter (Torres et al., 2016, 2017; Figure 2A). Although the FixLJ-FixK 2 cascade has been considered as the main regulator for nos genes in bradyrhizobia for a long time, the NasST two-component system has been revealed as an important regulator of nos transcription in response to $\mathrm{NO}_{3}{ }^{-}$ under both aerobic and anaerobic conditions (Sánchez et al., 2014, 2017; Figure 2A). The nasST operon encodes a $\mathrm{NO}_{3}{ }^{-}$ and $\mathrm{NO}_{2}{ }^{-}$sensor/transcriptional antitermination regulatory system. This system was initially considered to be involved in the $\mathrm{NO}_{3}{ }^{-} / \mathrm{NO}_{2}{ }^{-}$-responsive regulation of the nas genes for the $\mathrm{NO}_{3}{ }^{-}$assimilation pathway in bacteria, including B. diazoefficiens (Romeo et al., 2012; Wang et al., 2012; Luque-Almagro et al., 2013; Cabrera et al., 2016). A recent transcriptomic study using RNA-seq has shown that most of the genes whose expression changed in the $B$. diazoefficiens $\Delta$ nas $T$ mutant are related to $\mathrm{N}$ metabolism, especially amino acid transport (Sánchez et al., 2019).

NasS contains a $\mathrm{NO}_{3}{ }^{-} / \mathrm{NO}_{2}{ }^{-}$-binding motif similar to that of NrtA, which is the periplasmic component of an ABCtype system for $\mathrm{NO}_{3}{ }^{-}$and $\mathrm{NO}_{2}{ }^{-}$uptake in cyanobacteria (Koropatkin et al., 2006). NasT is an ANTAR (AmiR and NasR transcription antitermination regulator)-family protein (Shu and Zhulin, 2002). NasS and NasT form a complex that dissociates when NasS senses $\mathrm{NO}_{3}{ }^{-}$in micromolar concentrations (LuqueAlmagro et al., 2013; Sánchez et al., 2014; Hidaka et al., 2016). When $\mathrm{NO}_{3}{ }^{-}$is present, nos expression is markedly decreased $(\sim 70 \%)$ in the $\Delta$ nas $T$ background. In absence of $\mathrm{NO}_{3}{ }^{-}$, nos expression is induced in the $\triangle$ nas $S$ background but such induction is abolished with the additional deletion of nasT. Thus, $\mathrm{NO}_{3}-$ counteracts the NasS-mediated inhibition of nos by allowing the dissociation of the antiterminator NasT from the NasS-NasT complex (Sánchez et al., 2014, 2017; Figure 2). Then, the application of $n^{++}{ }^{+}$mutants (carrying a mutation in nasS) may be more effective than that of wild type nos ${ }^{+}$

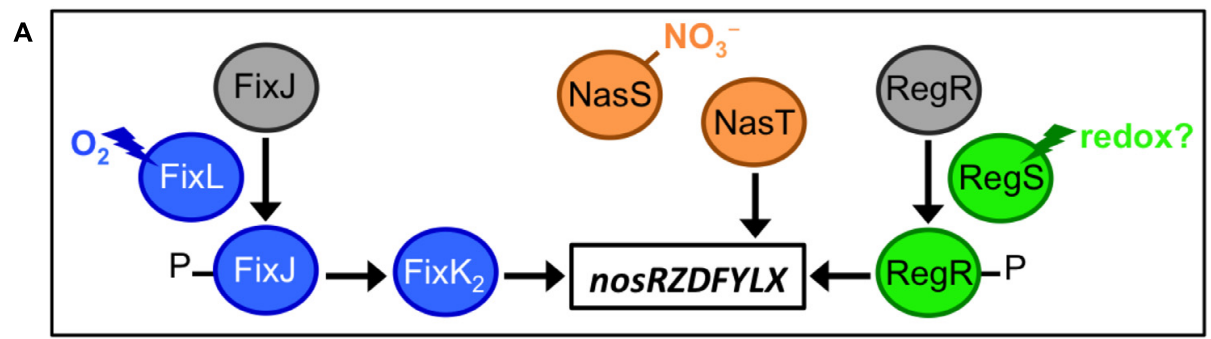

B

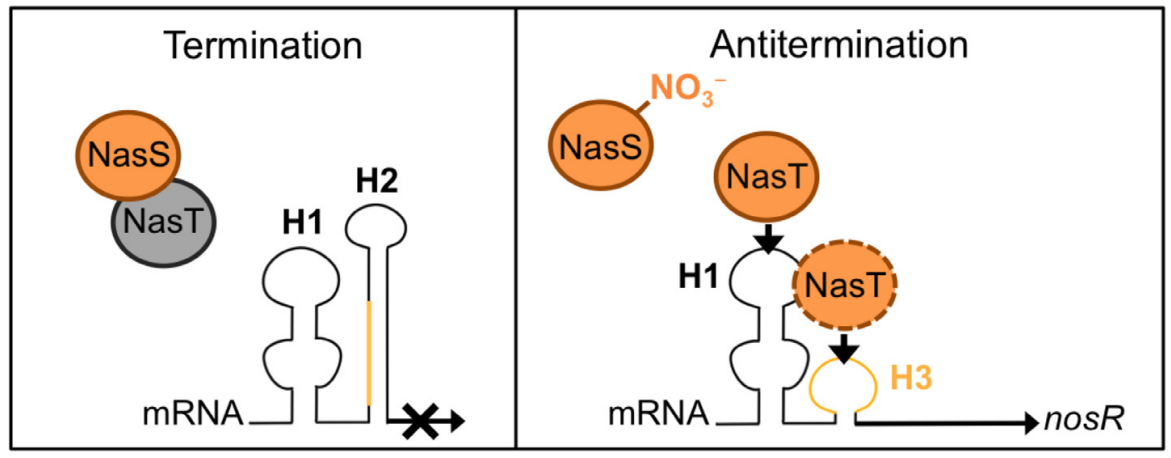

FIGURE 2 | Regulation of $\mathrm{N}_{2} \mathrm{O}$ reductase genes in bradyrhizobia. (A) Environmental factors and regulatory proteins involved in the control of nos expression. (B) The mechanism for NasT-mediated transcriptional antitermination of the nos genes. In the absence of nitrate $\left(\mathrm{NO}_{3}{ }^{-}\right)$, $\mathrm{NasT}^{\mathrm{T}}$ is sequestered by NasS; thus in the absence of NasT, the native conformation of the nosR-leader mRNA, which contains the $\mathrm{H} 1$ and $\mathrm{H} 2$ hairpins, is responsible for the termination of the nos transcription. When a certain level of $\mathrm{NO}_{3}{ }^{-}$is sensed by NasS, NasT is dissociated from NasS-NasT complex; the binding of NasT to $\mathrm{H} 1$ (and likely to H3 region, in orange) results in a conformational change in the mRNA that allows the read-through transcription of nos genes. 
alone if $\mathrm{NO}_{3}{ }^{-}$concentration in the rhizosphere is below the threshold for dissociation of the NasS-NasT complex. Although the concentration threshold in vitro is within the micromolar range (Hidaka et al., 2016), this concentration remains to be fixed under soil conditions.

When NasT is released from NasS, NasT interacts directly with a $5^{\prime}$-leader region of the nosR mRNA and interferes with the formation of a terminator structure, allowing a read-through transcription of nos genes (Sánchez et al., 2017; Figure 2B). The transcription terminator located upstream of nos $R$ comprises two RNA-hairpin structures ( $\mathrm{H} 1$ and $\mathrm{H} 2)$; the binding of NasT to $\mathrm{H} 1$ induces a conformational change in the terminator and facilitates read-through transcription to induce nos expression (Sánchez et al., 2017; Figure 2B). Deletion of either H1 or H2 increases nos expression in the absence or presence of $\mathrm{NO}_{3}{ }^{-}$ (Sánchez et al., 2014, 2017; Figure 2). Thus, theoretically, a B. diazoefficiens mutant defective in H1 (Figure 2B) would be an ideal nos ${ }^{++}$inoculant, because (i) it is expected to specifically induce nos genes, whereas nos ${ }^{++}$strains derived from nas $S$ mutations affected other genes controlled by the NasST system, and (ii) nos induction is independent of soil $\mathrm{NO}_{3}{ }^{-}$concentration (Itakura et al., 2013; Sánchez et al., 2017, 2019). Mutation of H1 may be applicable to other agriculturally important nos ${ }^{+}$bacteria such as Bradyrhizobium oligotrophicum S58, an endophyte of rice roots - where it potentially fixes $\mathrm{N}_{2}$ (Ohta and Hattori, 1983; Okubo et al., 2013; Sánchez et al., 2017; Sánchez and Minamisawa, 2018).

Furthermore, studies on $P$. denitrificans have shown that reduction of $\mathrm{N}_{2} \mathrm{O}$ to $\mathrm{N}_{2}$ is dependent on $\mathrm{Cu}$, a key cofactor of the Nos enzyme. Thus, bacterial cultures lacking $\mathrm{Cu}$ accumulate significant amounts of $\mathrm{N}_{2} \mathrm{O}$ (Felgate et al., 2012). Cu deficiency results in a decreased expression of nos $Z$ (Sullivan et al., 2013). Another key factor is the $\mathrm{pH}$ that significantly affects $\mathrm{N}_{2} \mathrm{O}$ emission from microbes. The expression of functional $\mathrm{N}_{2} \mathrm{OR}$ is difficult at low pH (Bakken et al., 2012). Sinorhizobium meliloti, the alfalfa endosymbiont, is unable to express $\mathrm{N}_{2} \mathrm{OR}$ at $\mathrm{pH} 6$ (Bueno et al., 2015). In P. denitrificans, $\mathrm{pH}$ has little effect on the transcription of the nos $Z$, but may have a direct posttranslational effect on the assembly and/or activity of the $\mathrm{N}_{2} \mathrm{OR}$ holoenzyme (Bakken et al., 2012). The effect of $\mathrm{Cu}$ or $\mathrm{pH}$ on the reduction of $\mathrm{N}_{2} \mathrm{O}$ to $\mathrm{N}_{2}$ in $B$. diazoefficiens is currently unknown. Among the environmental factors that affect the bacterial $\mathrm{N}_{2} \mathrm{OR}$ activity, very little is known about the effect of availability and redox state of carbon sources. In this context, the response regulator RegR of the RegSR two-component regulatory system appears to induce nos expression in $B$. diazoefficiens, most likely in response to redox state (Torres et al., 2016; Figure 2A).

\section{FUTURE DIRECTIONS FOR PRODUCTION OF BRADYRHIZOBIAL INOCULANTS FOR $\mathrm{N}_{2} \mathrm{O}$ MITIGATION}

The understanding of $\mathrm{N}_{2} \mathrm{O}$ production in the soybean rhizosphere has been significantly advanced. A variety of techniques, such as functional omics, ${ }^{15} \mathrm{~N}$ isotope analysis, and zymography, will facilitate a better understanding of the players and processes for $\mathrm{N}$ transformation in the soybean rhizosphere of degrading nodules. In addition, further studies on soil factors that control the amount and distribution of soybean bradyrhizobia in the rhizosphere are required because they are key determinants for the flux of $\mathrm{N}_{2} \mathrm{O}$ during nodule decomposition (Inaba et al., 2012).

Shiina et al. (2014) reported that the soil type determines the occurrence of $B$. diazoefficiens $\left(n o s^{+}\right)$or $B$. japonicum $\left(n o s^{-}\right)$in Japanese soybean fields; the $\operatorname{nos}^{+}$bradyrhizobia are predominant in Gleysol (wetland soils where water regime causes low-oxygen conditions), whereas the nos ${ }^{-}$bradyrhizobia are predominant in Andosols (volcanic soils containing porous sediments, resulting in more aerated conditions). Saeki et al. (2017) reported that the presence of nos in B. diazoefficiens confers a competitive advantage in flooded soils with low-oxygen conditions, similar to Gleysol soils. However, batch experiments suggested that $B$. japonicum may be less competitive compared to $B$. diazoefficiens due to energy depletion under anaerobic conditions, which is associated with a marked impairment of Nap activity in B. japonicum and not with the absence of nos (Siqueira et al., 2017). These findings emphasize the need for further research on how soil factors influence the relevance of the $\mathrm{N}_{2} \mathrm{O}$ reduction step in bradyrhizobial competition.

Significant advances have led to the use of bradyrhizobial $\mathrm{N}_{2} \mathrm{OR}$ as an $\mathrm{N}_{2} \mathrm{O}$ sink in soybean ecosystems. Following the work done by Itakura et al. (2013) and Akiyama et al. (2016), promising strategies for production of rhizobial inoculants for $\mathrm{N}_{2} \mathrm{O}$ mitigation would be the selection of superior native strains (in terms of adaptation to local environments and $\mathrm{N}_{2}$-fixing symbiotic efficiency) and the optimization of $\mathrm{N}_{2} \mathrm{O}$ reduction activity through appropriate genetic modification or management of soil chemical and physical properties. However, generating mutants requires more time, cost, and technical skill than isolating nos $^{+}$strains from local soybean fields (Itakura et al., 2013; Akiyama et al., 2016). Moreover, inoculating a mixture of native strains provides more adaptability than a single strain (Akiyama et al., 2016). Thus, isolating nos ${ }^{+}$ strains from local fields is more feasible for many soybeanproducing countries and is potentially applicable to other ecosystems. Indeed, it has already been suggested the potential activity of Ensifer (formerly Sinorhizobium) meliloti, the alfalfa endosymbiont (Bueno et al., 2015).

\section{AUTHOR CONTRIBUTIONS}

Both authors have contributed equally to the discussion, writing, and approving the manuscript.

\section{FUNDING}

This work was supported by a Grant-in-Aid for Scientific Research (A) 26252065 and (B) $18 \mathrm{H} 02112$ from the Ministry of Education, Culture, Sports, Science and Technology, Japan, and by grants from the Project of the NARO Bio-oriented Technology Research Advancement Institution (Research Program on Development of Innovative Technology). 


\section{REFERENCES}

Akiyama, H., Hoshino, Y. T., Itakura, M., Shimomura, Y., Wang, Y., Yamamoto, A., et al. (2016). Mitigation of soil N2O emission by inoculation with a mixed culture of indigenous Bradyrhizobium diazoefficiens. Sci. Rep. 6:32869. doi: 10.1038/srep3286910.1038/srep32869

Argaw, A. (2014). Symbiotic effectiveness of inoculation with Bradyrhizobium isolates on soybean [Glycine max (L.) Merrill] genotypes with different maturities. Springer Plus. 3:753. doi: 10.1186/2193-1801-3-753

Badr, O., and Probert, S. D. (1992). Nitrous oxide in the Earth's atmosphere. Appl. Energ. 41, 177-200. doi: 10.1016/0306-2619(92)90002-s

Bakken, L. R., Bergaust, L., Liu, B., and Frostegard, § (2012). Regulation of denitrification at the cellular level: a clue to the understanding of $\mathrm{N} 2 \mathrm{O}$ emissions from soils Phil. Trans. R. Soc. B. 367, 1224-1234. doi: 10.1098/rstb.2011.0321

Bakker, P. A., Berendsen, R. L., Doornbos, R. F., Wintermans, P. C., and Pieterse, C. M. (2013). The rhizosphere revisited: root microbiomics. Front. Plant Sci. 4:165. doi: $10.3389 /$ fpls.2013.00165

Bueno, E., Mania, D., Frostegard, Å, Bedmar, E. J., Bakken, L. R., and Delgado, M. J. (2015). Anoxic growth of Ensifer meliloti 1021 by N2O-reduction, a potential mitigation strategy. Front. Microbiol. 6:537. doi: 10.3389/fmicb.2015.00537

Cabrera, J. J., Salas, A., Torres, M. J., Bedmar, E. J., Richardson, D. J., Gates, A. J., et al. (2016). An integrated biochemical system for nitrate assimilation and nitric oxide detoxification in Bradyrhizobium japonicum. Biochem. J. 473, 297-309. doi: 10.1042/BJ20150880

Ciampitti, I. A., Ciarlo, E. A., and Conti, M. E. (2008). Nitrous oxide emissions from soil during soybean [(Glycine max (L.) Merrill] crop phenological stages and stubbles decomposition period. Biol. Fertil. Soils 44, 581-588. doi: 10.1007/ s00374-007-0241-7

Delamuta, J. R., Ribeiro, R. A., Ormeñbo-Orrillo, E., Melo, I. S., Martínez-Romero, E., and Hungria, M. (2013). Polyphasic evidence supporting the reclassification of Bradyrhizobium japonicum group Ia strains as Bradyrhizobium diazoefficiens sp. nov. Int. J. Syst. Evol. Microbiol. 63, 3342-3351. doi: 10.1099/ijs.0.049130-0

Felgate, H., Giannopoulos, G., Sullivan, M. J., Gates, A. J., Clarke, T. A., Baggs, E., et al. (2012). The impact of copper, nitrate and carbon status on the emission of nitrous oxide by two species of bacteria with biochemically distinct denitrification pathways. Environ. Microbiol. 14, 1788-1800. doi: 10.1111/j. 1462-2920.2012.02789.x

Gaimster, H., Alston, M., Richardson, D. J., Gates, A. J., and Rowley, G. (2018). Transcriptional and environmental control of bacterial denitrification and N2O emissions. FEMS Microbiol. Lett. 365:fnx277. doi: 10.1093/femsle/fnx277

Graf, D. R., Jones, C. M., and Hallin, S. (2014). Intergenomic comparisons highlight modularity of the denitrification pathway and underpin the importance of community structure for N2O emissions. PLoS One 9:e114118. doi: 10.1371/ journal.pone. 0114118

Hartmann, A., Rothballer, S., and Schmid, M. (2008). Lorenz Hiltner, a pioneer in rhizosphere microbial ecology and soil bacteriology research. Plant Soil 312, 7-14. doi: 10.1007/s11104-007-9514-z

Hénault, C., Grossel, A., Mary, B., Roussel, M., and Leonard, J. (2012). Nitrous oxide emission by agricultural soils: a review of spatial and temporal variability for mitigation. Pedosphere 22, 426-433. doi: 10.1016/s1002-0160(12)60029-0

Hénault, C., and Revellin, C. (2011). Inoculants of leguminous crops for mitigating soil emissions of the greenhouse gas nitrous oxide. Plant Soil 346, 289-296. doi: 10.1007/s11104-011-0820-0

Hidaka, M., Gotoh, A., Shimizu, T., Minamisawa, K., Imamura, H., and Uchida, T. (2016). Visualization of NO3-/NO2- dynamics in living cells by fluorescence resonance energy transfer (FRET) imaging employing a rhizobial two-component regulatory system. J. Biol. Chem. 291, 2260-2269. doi: 10.1074/ jbc.M115.687632

Hirayama, J., Eda, S., Mitsui, H., and Minamisawa, K. (2011). Nitratedependent $\mathrm{N} 2 \mathrm{O}$ emission from intact soybean nodules via denitrification by Bradyrhizobium japonicum bacteroids. Appl. Environ. Microbiol. 77, 8787-8790. doi: 10.1128/aem.06262-11

Inaba, S., Ikenishi, F., Itakura, M., Kikuchi, M., Eda, S., Chiba, N., et al. (2012). $\mathrm{N} 2 \mathrm{O}$ emission from degraded soybean nodules depends on denitrification by Bradyrhizobium japonicum and other microbes in the rhizosphere. Microbes Environ. 27, 470-476. doi: 10.1264/jsme2.me12100

Inaba, S., Tanabe, K., Eda, S., Ikeda, S., Higashitani, A., Mitsui, H., et al. (2009). Nitrous oxide emission and microbial community in the rhizosphere of nodulated soybeans during the late growth period. Microbes Environ. 24, 64-67. doi: 10.1264/jsme2.me08544

Intergovernmental Panel on Climate Change [IPCC], (2014). Climate change 2014: Synthesis Report. Contribution of Working Groups I, II and III to the Fifth Assessment Report of the Intergovernmental Panel on Climate Change. Geneva: IPCC.

Itakura, M., Tabata, K., Eda, S., Mitsui, H., Murakami, K., Yasuda, J., et al. (2008). Generation of Bradyrhizobium japonicum mutants with increased N2O reductase activity by selection after introduction of a mutated dnaQ gene. Appl. Environ. Microbiol. 74, 7258-7264. doi: 10.1128/AEM.01850-08

Itakura, M., Uchida, Y., Akiyama, H., Takada-Hoshino, Y., Shimomura, Y., Morimoto, S., et al. (2013). Mitigation of nitrous oxide emissions from soils by Bradyrhizobium japonicum inoculation. Nat. Clim. Chan. 3, 208-212. doi: 10.1038/nclimate1734

Koropatkin, N. M., Pakrasi, H. B., and Smith, T. J. (2006). Atomic structure of a nitrate-binding protein crucial for photosynthetic productivity. Proc. Natl. Acad. Sci. U.S.A. 103, 9820-9825. doi: 10.1073/pnas.0602517103

LeBauer, D. S., and Treseder, K. (2008). Nitrogen limitation of net primary productivity in terrestrial ecosystems is globally distributed. Ecology 89, 371-379. doi: 10.1890/06-2057.1

Luque-Almagro, V. M., Lyall, V. J., Ferguson, S. J., Roldán, M. D., and Richardson, D. J. (2013). Nitrogen oxyanion-dependent dissociation of a two-component complex that regulates bacterial nitrate assimilation. J. Biol. Chem. 288, 2969229702. doi: 10.1074/jbc.M113.459032

Ohta, H., and Hattori, T. (1983). Agromonas oligotrophica gen. nov., sp. nov., a nitrogen-fixing oligotrophic bacterium. Antonie Van Leeuwenhoek 49, 429-446.

Okubo, T., Fukushima, S., Itakura, M., Oshima, K., Longtonglang, A., Teaumroong, N., et al. (2013). Genome analysis suggests that the soil oligotrophic bacterium Agromonas oligotrophica (Bradyrhizobium oligotrophicum) is a nitrogen-fixing symbiont of Aeschynomene indica. Appl. Environ. Microbiol. 79, 2541-2551. doi: 10.1128/AEM.00009-13

Richardson, D. J., Felgate, H., Watmough, N., Thomson, A., and Baggs, E. (2009). Mitigating release of the potent greenhouse gas N2O from the nitrogen cyclecould enzymatic regulation hold the key? Trends Biotechnol. 27, 388-397. doi: 10.1016/j.tibtech.2009.03.009

Romeo, A., Sonnleitner, E., Sorger-Domenigg, T., Nakano, M., Eisenhaber, B., and Bläsi, U. (2012). Transcriptional regulation of nitrate assimilation in Pseudomonas aeruginosa occurs via transcriptional antitermination within the nirBD-PA1779-cobA operon. Microbiology 158, 1543-1552. doi: 10.1099/mic.0. 053850-0

Saeki, Y., Nakamura, M., Mason, M. L. T., Yano, T., Shiro, S., Sameshima-Saito, R., et al. (2017). Effect of flooding and the nosZ gene in bradyrhizobia on bradyrhizobial community structure in the soil. Microbes Environ. 32, 154-163. doi: 10.1264/jsme2.ME16132

Sameshima-Saito, R., Chiba, K., Hirayama, J., Itakura, M., Mitsui, H., Eda, S., et al. (2006a). Symbiotic Bradyrhizobium japonicum reduces N2O surrounding the soybean root system via nitrous oxide reductase. Appl. Environ. Microbiol. 72, 2526-2532. doi: 10.1128/aem.72.4.2526-2532.2006

Sameshima-Saito, R., Chiba, K., and Minamisawa, K. (2006b). Correlation of denitrifying capability with the existence of nap, nir, nor and nos genes in diverse strains of soybean bradyrhizobia. Microbes Environ. 21, 174-184. doi: 10.1264/jsme2.21.174

Sameshima-Saito, R., Chiba, K., and Minamisawa, K. (2004). New method of denitrification analysis of Bradyrhizobium field isolates by gas chromatographic determination of 15N-labeled N2. Appl. Environ. Microbiol. 70, 2886-2891. doi: 10.1128/aem.70.5.2886-2891.2004

Sánchez, C., Bedmar, E. J., and Delgado, M. J. (2011). "Denitrification in legumeassociated endosymbiotic bacteria," in Nitrogen Cycling in Bacteria: Molecular Analysis, ed. J. W. B. Moir (Norfolk: Caister Academic Press), 197-210.

Sánchez, C., Itakura, M., Mitsui, H., and Minamisawa, K. (2013). Linked expressions of nap and nos genes in a Bradyrhizobium japonicum mutant with increased N2O reductase activity. Appl. Environ. Microbiol. 79, 4178-4180. doi: 10.1128/AEM.00703-13

Sánchez, C., Itakura, M., Okubo, T., Matsumoto, T., Yoshikawa, H., Gotoh, A., et al (2014). The nitrate-sensing NasST system regulates nitrous oxide reductase and periplasmic nitrate reductase in Bradyrhizobium japonicum. Environ. Microbiol. 16, 3263-3274. doi: 10.1111/1462-2920.12546 
Sánchez, C., and Minamisawa, K. (2018). Redundant roles of Bradyrhizobium oligotrophicum $\mathrm{Cu}$-type (NirK) and $\mathrm{cd}_{1}$-type $(\mathrm{NirS})$ nitrite reductase genes under denitrifying conditions. FEMS Microbiol. Lett. 365:fny015. doi: 10.1093/ femsle/fny015

Sánchez, C., Mitsui, H., and Minamisawa, K. (2017). Regulation of nitrous oxide reductase genes by NasT-mediated transcription antitermination in Bradyrhizobium diazoefficiens. Environ. Microbiol. Rep. 9, 389-396. doi: 10. 1111/1758-2229.12543

Sánchez, C., Siqueira, A. F., Mitsui, H., and Minamisawa, K. (2019). Identification of genes regulated by the antitermination factor NasT during denitrification in Bradyrhizobium diazoefficiens. Microbes Environ. doi: 10.1111/1758-2229. 12543 [Epub ahead of print].

Shiina, Y., Itakura, M., Choi, H., Seaki, Y., Hayatsu, M., and Minamisawa, K. (2014). Relationship between soil type and N2O reductase genotype (nosZ) of indigenous soybean bradyrhizobia: nosZ-minus populations are dominant in Andosols. Microbes Environ. 29, 420-426. doi: 10.1264/jsme2.ME14130

Shu, C. Y. J., and Zhulin, I. B. (2002). ANTAR: an RNA-binding domain in transcription antitermination regulatory proteins. Trends Biochem. Sci. 27, 3-5. doi: 10.1016/s0968-0004(01)02036-9

Siqueira, A. F., Minamisawa, K., and Sánchez, C. (2017). Anaerobic reduction of nitrate to nitrous oxide is lower in Bradyrhizobium japonicum than in Bradyrhizobium diazoefficiens. Microbes Environ. 32, 398-401. doi: 10.1264/ jsme2.me17081

Sullivan, M. J., Gates, A. J., Appia-Ayme, C., Rowley, G., and Richardson, D. J. (2013). Copper control of bacterial nitrous oxide emission and its impact on vitamin B12-dependent metabolism. Proc. Natl. Acad. Sci. U.S.A. 110, 1992619931. doi: 10.1073/pnas. 1314529110

Thomson, A. J., Giannopoulos, G., Pretty, J., Baggs, E. M., and Richardson, D. J. (2012). Biological sources and sinks of nitrous oxide and strategies to mitigate emissions. Phil. Trans. R. Soc. B. 367, 1157-1168. doi: 10.1098/rstb.2011.0415

Torres, M. J., Bueno, E., Jiménez-Leiva, A., Cabrera, J. J., Bedmar, E. J., Mesa, S., et al. (2017). FixK2 is the main transcriptional activator of Bradyrhizobium diazoefficiens nosRZDYFLX genes in response to low oxygen. Front. Microbiol. 8:1621. doi: 10.3389/fmicb.2017.01621

Torres, M. J., Simon, J., Rowley, G., Bedmar, E. J., Richardson, D. J., Gates, A. J., et al. (2016). Nitrous oxide metabolism in nitrate-reducing bacteria: physiology and regulatory mechanisms. Adv. Microb. Physiol. 68, 353-432. doi: 10.1016/bs. ampbs.2016.02.007

Tortosa, G., Hidalgo, A., Salas, A., Bedmar, E. J., Mesa, S., and Delgado, M. J. (2016). Nitrate and flooding induce N2O emissions from soybean nodules. Symbiosis 67, 125-133. doi: 10.1007/s13199-015-0341-3

Uchida, Y., and Akiyama, H. (2013). Mitigation of postharvest nitrous oxide emissions from soybean ecosystems: a review. Soil Sci. Plant Nutr. 59, 477-487. doi: 10.1080/00380768.2013.805433

Velasco, L., Mesa, S., Xu, C. A., Delgado, M. J., and Bedmar, E. J. (2004). Molecular characterization of nosRZDFYLX genes coding for denitrifying nitrous oxide reductase of Bradyrhizobium japonicum. Antonie Van Leeuwenhoek 85, 229235. doi: 10.1023/b:anto.0000020156.42470.db

Wang, B., Pierson, L. S. III, Rensing, C., Gunatilaka, M. K., and Kennedy, C. (2012). NasT-mediated antitermination plays an essential role in the regulation of the assimilatory nitrate reductase operon in Azotobacter vinelandii. Appl. Environ. Microbiol. 78, 6558-6567. doi: 10.1128/AEM.017 20-12

Yang, L., and Cai, Z. (2005). The effect of growing soybean (Glycine max. L.) on N2O emission from soil. Soil Biol. Biochem. 37, 1205-1209. doi: 10.1016/j. soilbio.2004.08.027

Zumft, W. G. (1997). Cell biology and molecular basis of denitrification. Microbiol. Mol. Biol. R. 61, 533-616.

Zumft, W. G., and Kroneck, P. M. (2007). Respiratory transformation of nitrous oxide (N2O) to dinitrogen by bacteria and archaea. Adv. Microb. Physiol. 52, 107-227. doi: 10.1016/s0065-2911(06)52003-x

Conflict of Interest Statement: The authors declare that the research was conducted in the absence of any commercial or financial relationships that could be construed as a potential conflict of interest.

Copyright (c) 2019 Sánchez and Minamisawa. This is an open-access article distributed under the terms of the Creative Commons Attribution License (CC BY). The use, distribution or reproduction in other forums is permitted, provided the original author(s) and the copyright owner(s) are credited and that the original publication in this journal is cited, in accordance with accepted academic practice. No use, distribution or reproduction is permitted which does not comply with these terms. 